\title{
ENHANCED EFFECT OF CHEMICALLY MODIFIED COLLAGEN SUBSTRATUM ON ATTACHMENT AND GROWTH OF FIBROBLASTS IN SERUM-FREE MEDIUM
}

\author{
SHUNJI KASAI ${ }^{1}$, TERUO MIYATA ${ }^{2}$, TAKEHIKO KUNIMOTO ${ }^{3}$ and KAZUO NITTA ${ }^{3}$ \\ ${ }^{1}$ Department of System Engineering for Materials, Faculty of Technology, Tokyo University of Agriculture \\ and Technology, Koganei, Tokyo 184, 2 Japan Biomedical Material Research Center, Nakane, Meguroku, \\ Tokyo 152, and ${ }^{3}$ Chemotherapy Division, National Cancer Center Research Institute, Tsukiji, Chuoku, \\ Tokyo 104, Japan
}

\begin{abstract}
We studied the effects of chemical modifications of the collagen substratum on the attachment, spreading, and proliferation of fibroblasts (L cells). Succinylation and methylation of collagen enhanced the attachment rate of $L$ cells in serum-free medium. Cell attachment to heat-denatured collagen was markedly enhanced by the presence of serum or plasma fibronectin. Therefore, alteration of the net charge of collagen affects cell attachment directly, and conformational change of the collagen triplehelical structure through fibronectin does so indirectly. Furthermore, the number of cells maintained on succinylated and methylated collagens in serum-free medium was 8.8-fold and 7.4-fold greater, respectively, than in cultures maintained on unmodified collagen. The results suggest that chemical modifications of the collagen side chains not only promote the attachment of $\mathrm{L}$ cells to the substrata but also directly affect cell proliferation.
\end{abstract}

Collagen is a major component of the extracellular matrix in living tissues. Collagen can influence the adhesion $(10,14)$, morphology $(2,23)$, and migration (18), and in some cases, differentiation $(7,15)$ of cells. Furthermore, it appears that growth factors are not required if certain cells are maintained on a substratum of type IV collagen (19) or the extracellular matrix (5).

Chemical modifications of collagen side chains have been shown to affect the adhesion of platelets to the substrata (13), but very few studies have been reported on the interaction of other types of cells with chemically modified collagens.

Recently, we observed that succinylation and methylation of collagen side chains promoted

${ }^{1}$ Present address: Biotechnology Center, The Green Cross Corporation Research Division, Hirakata, Osaka 573, Japan the adhesion of macrophages to the substrata, regardless of the presence or absence of serum (manuscript in preparation). In this study, chemically modified collagens were used as substrata for the culture of fibroblasts in serumfree medium and the behavior of fibroblasts on the substrata is discussed. Clear differences were observed in cell attachment, spreading, and proliferation between unmodified collagen and chemically modified collagens used as substrata.

\section{MATERIALS AND METHODS}

\section{Materials}

Eagle's minimal essential medium (Eagle's MEM) and Hanks' balanced salt solution (HBSS) were purchased from Nissui Seiyaku Co. Fetal calf serum (FCS) and trypsin were obtained from Grand Island Biological Co. Bovine serum albumin (BSA) was purchased from Sigma Chemical Co. 


\section{Purification of Plasma Fibronectin}

Plasma fibronectin was purified from human plasma by gelatin affinity chromatography (3, 4). Fifty milliliters of human plasma were passed through a $1.6 \times 70-\mathrm{cm}$ column of plain Sepharose $4 \mathrm{~B}$ before fractionation on gelatinSepharose 4B to remove materials binding to Sepharose. The same volume of effluent plasma from plain Sepharose 4B was passed through a $1.6 \times 20-\mathrm{cm}$ column of gelatinSepharose 4B in phosphate-buffered saline (PBS) ( $\mathrm{pH} 7.2$ ), containing $0.01 \mathrm{M}$ sodium citrate at room temperature. After the column was washed with PBS containing $0.01 \mathrm{M}$ sodium citrate and $1 \mathrm{M}$ urea in $0.05 \mathrm{M}$ Tris- $\mathrm{HCl}(\mathrm{pH}$ 7.5), the adsorbed fibronectin was eluted with $4 \mathrm{M}$ urea in $0.05 \mathrm{M}$ Tris- $\mathrm{HCl}(\mathrm{pH} \mathrm{7.5)}$. The eluate was dialyzed at room temperature against PBS and stored at $-20^{\circ} \mathrm{C}$. Estimation by sodium dodecyl sulfate-polyacrylamide gel electrophoresis (SDS-PAGE) indicated the purity of isolated plasma fibronectin to be more than $90 \%$.

\section{Preparation of Collagen and Chemical Modi- fications of Collagen Side Chains}

Calf-skin insoluble collagen can be solubilized by pepsin at $\mathrm{pH} 3$ at room temperature. The solubilized collagen was purified by filtration through a $1-\mu \mathrm{m}$ Millipore filter and by precipitation at $\mathrm{pH} 7$ (16). Monomeric dispersed collagen (unmodified collagen) was chemically modified by methylation or succinylation (22). Collagen was methylated by treating lyophilized collagen with dehydrated methanol containing $0.1 \mathrm{~N}$ hydrochloric acid for 7 days at room temperature. The methylated collagen was precipitated at $\mathrm{pH} 10.5$ from acidic solution and purified by reprecipitation. Collagen was succinylated by adding $2 \%$ succinic anhydride in acetone to collagen suspension at $\mathrm{pH} 9$. The succinylated collagen was precipitated at $\mathrm{pH} 4.2$ and purified by reprecipitation. A collagen solution was prepared according to the method of Michalopoulos and Pitot (12). Unmodified, succinylated, or methylated collagen $(0.1 \mathrm{~g})$ was solubilized in $50 \mathrm{ml}$ of sterile $0.1 \%$ acetic acid in $\mathrm{H}_{2} \mathrm{O}$ and stirred at $4^{\circ} \mathrm{C}$ for $48 \mathrm{~h}$. The supernatant after centrifugation at $10,000 \mathrm{~g}$ for $30 \mathrm{~min}$ was the stock collagen solution.

\section{Collagen-Coated Substrata}

Collagen-coated substrata were prepared accord- ing to the method of Grinnell and Minter (6), with slight modifications. Aliquots $(0.8 \mathrm{ml})$ of a collagen solution, $0.5 \mathrm{mg} / \mathrm{ml}$ in $0.1 \%$ acetic acid, were incubated in $35-\mathrm{mm}$ Nunc culture dishes for $20 \mathrm{~min}$ at $22^{\circ} \mathrm{C}$, after which the dishes were rinsed three times with HBSS.

\section{Heat-Denatured Collagen-Coated Substrata}

Aliquots $(0.8 \mathrm{ml})$ of a collagen solution, $0.5 \mathrm{mg} /$ $\mathrm{ml}$ in $0.1 \%$ acetic acid, were heated to $50^{\circ} \mathrm{C}$ for $20 \mathrm{~min}$. The solutions were then cooled to $37^{\circ} \mathrm{C}$ and incubated in dishes for $20 \mathrm{~min}$ at $22^{\circ} \mathrm{C}$, after which the dishes were rinsed three times with HBSS. To see the effect of fibronectin, $0.5 \mathrm{ml}$ of plasma fibronectin solution at a concentration at $100 \mu \mathrm{g} / \mathrm{ml}$ in HBSS was added to the heat-denatured collagen-coated substrata, incubated overnight at $4^{\circ} \mathrm{C}$, and washed twice with HBSS before addition of the cells.

\section{Cells}

$\mathrm{L}$ cells were grown in stationary culture in Eagle's MEM supplemented with $10 \%$ FCS and $60 \mu \mathrm{g}$ of kanamycin per $\mathrm{ml}$.

\section{The Kinetics of Cell Attachment}

$\mathrm{L}$ cells were dispersed from the monolayer with $0.25 \%$ trypsin and $0.02 \%$ ethylenediaminetetraacetate (EDTA) in PBS. The detached cells were harvested by centrifugation, washed once with HBSS containing BSA at $10 \mathrm{mg} / \mathrm{ml}$, and resuspended in Eagle's MEM with or without $10 \%$ FCS. L cells $\left(5 \times 10^{5}\right.$ cells $)$ in $1.5 \mathrm{ml}$ of adhesion medium were placed in various collagen-coated dishes. The dishes were incubated at $37^{\circ} \mathrm{C}$ in a $5 \% \mathrm{CO}_{2}$ atmosphere. The number of adherent cells was determined at various times by counting the number of nonadherent cells recovered in the medium and subtracting this number from the number of cells initially placed in the dish (20).

\section{Cell Number in Serum-Free Medium}

For growth assay, $L$ cells $\left(1.5 \times 10^{4}\right.$ cells $)$ suspended in Eagle's MEM supplemented with $1 \%$ BSA were placed into $16 \mathrm{~mm}$-wells of flatbottom multiwell plates (Flow Linbro) that had been coated with various collagens and/or fibronectin, and incubated at $37^{\circ} \mathrm{C}$ in a $5 \% \mathrm{CO}_{2}$ atmosphere. At the end of the incubations the medium was decanted and the cells were released 
with $0.25 \%$ trypsin and $0.02 \%$ EDTA in PBS. The number of released cells was counted in a hemocytometer.

\section{RESULTS}

The Net Charge on Unmodified and Chemically Modified Collagen

To check for the helical stability of collagen during various chemical modification procedures, each collagen solution was assayed by circular dichroism (CD). The CD spectrum of succinylated or methylated collagen was similar to that of unmodified collagen, having a positive peak at $220 \mathrm{~nm}$ and a negative deflection below $210 \mathrm{~nm}$ (Fig. 1). It was concluded, therefore, that none of the chemical modifications caused any conformational change in collagen.

Carboxyl and $\epsilon$-amino groups of unmodified and chemically modified collagen were determined by hydrogen ion titration (21) and the 2,4,6-trinitrobenzene sulfonic acid colorimetric method (9), respectively. Fig. 2 shows the results of analysis of the carboxyl and $\epsilon$-amino groups of unmodified and chemically modified

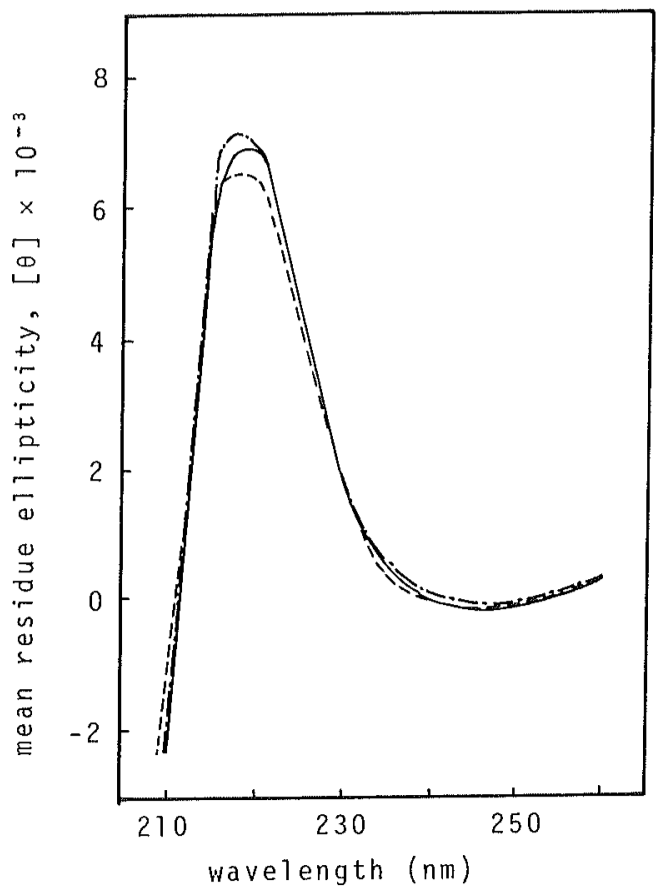

Fig. 1 CD spectra of chemically modified collagen. Each sample of collagen was dissolved in $10 \mathrm{mM}$ phosphate buffer ( $\mathrm{pH} 3)$, Values for $[\theta]$ are deg. $\mathrm{cm}^{2} \cdot \mathrm{dmol}^{-1}$. Unmodified collagen $(-)$; succinylated collagen (--); methylated collagen (--)

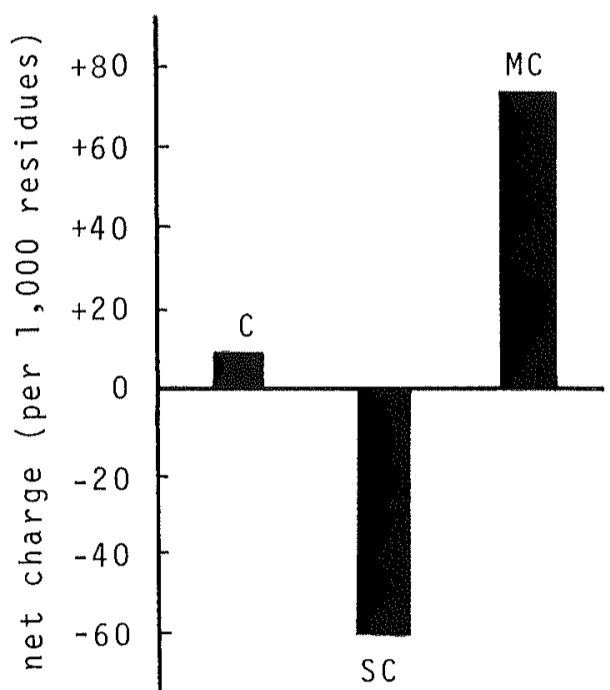

Fig. 2 The net charge on unmodified and chemically modified collagen. The net charge was calculated for $\mathrm{pH} 7.3$ on the basis of 1,000 amino acid residues. Carboxyl and $\epsilon$-amino groups of unmodified and chemically modified collagen were determined by hydrogen ion titration (17) and the 2,4,6-trinitrobenzene sulfonic acid colorimetric method (18), respectively. $C$, unmodified collagen; $\mathrm{SC}$, succinylated collagen; MC, methylated collagen

collagens. At $\mathrm{pH} 7.3$ the net charge on unmodified, succinylated, and methylated collagen was approximately neutral, negative, and positive, respectively.

\section{Effect of Chemical Modifications of Collagen on Cell Attachment}

$\mathrm{L}$ cells attached more rapidly to methylated (with net positive charge) collagen-coated substrata than to succinylated (with net negative charge) collagen-coated substrata in the presence or absence of serum (Fig. 3). However, as the incubation time increased, the rate of cell attachment to succinylated collagen-coated substrata was markedly increased. After $1 \mathrm{~h}$ of incubation more than $85 \%$ of the cells attached to succinylated collagen-coated substrata, just as in the case of methylated collagen-coated substrata in the presence of serum. In contrast, fewer cells attached to unmodified collagen which is approximately neutral in net charge, and the attachment did not exceed $35 \%$ after $1 \mathrm{~h}$ of incubation.

On unmodified collagen-coated substrata, partial or no cell spreading was observed regardless of the presence or absence of serum. On 
A

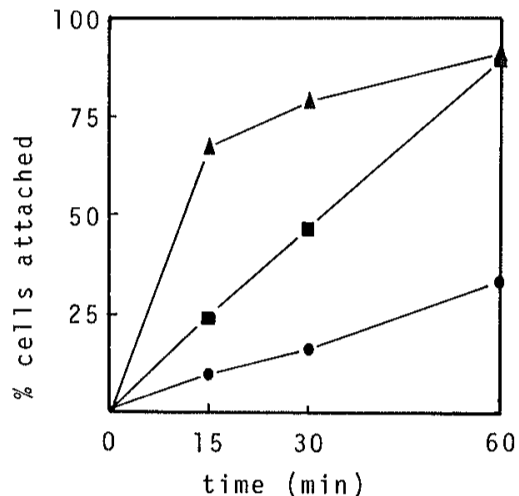

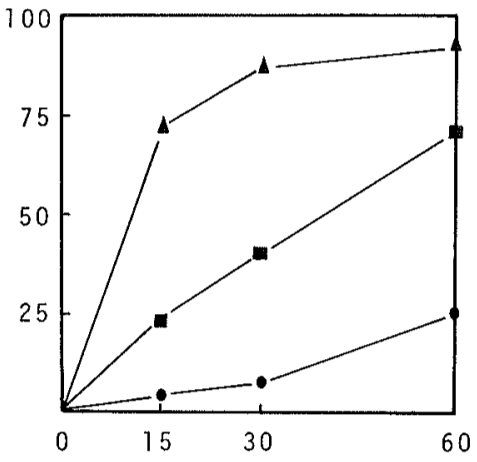

Fig. 3 Time course of L cell attachment to chemically modified collagen substrata in the presence (A) or absence (B) of serum. • , unmodified collagen substratum; $\boldsymbol{\square}$, succinylated collagen substratum; $\mathbf{\Lambda}$, methylated collagen substratum

the other hand, succinylation or methylation of collagen promoted cell spreading on the substrata regardless of the presence or absence of serum (Fig. 4). These results indicate that the alteration of the net charge of collagen markedly affects the rate of cell attachment and spreading, regardless of the presence or absence of serum.
A

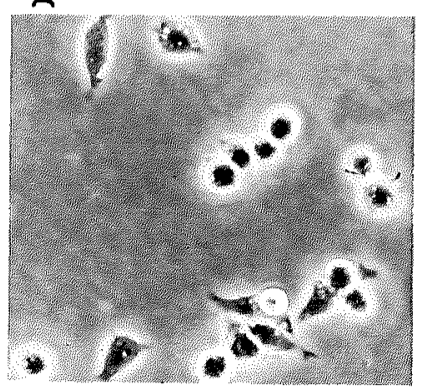

D

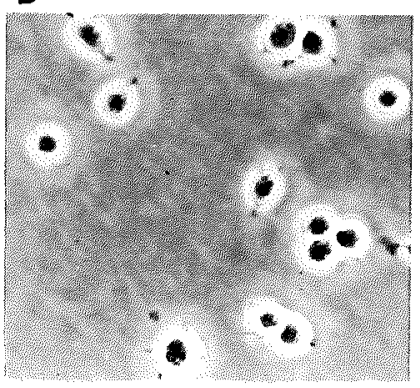

B
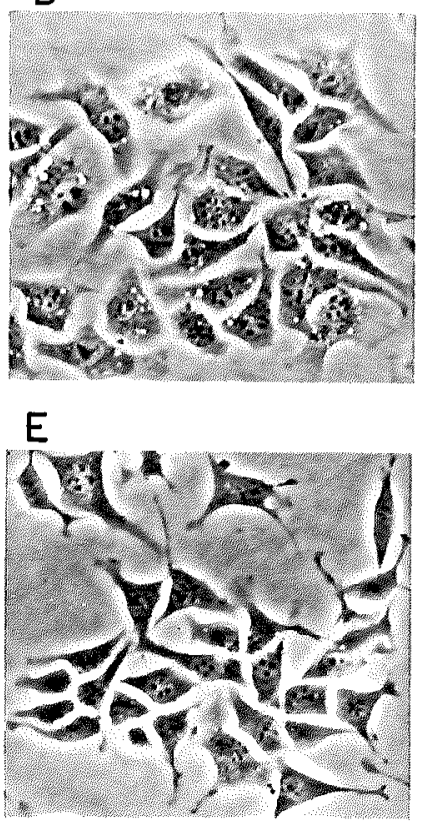

C

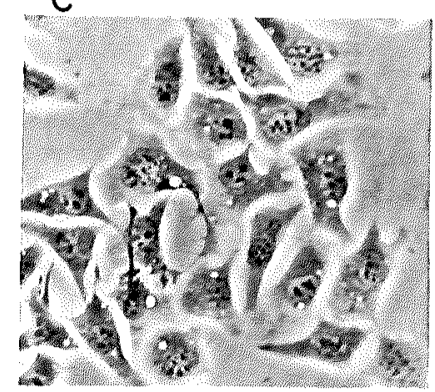

F

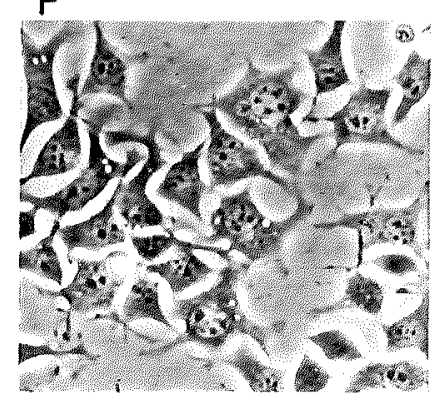

Fig. 4 L cell spreading on the substratum coated with unmodified or chemically modified collagen. Cells were incubated at $37^{\circ} \mathrm{C}$ for $1 \mathrm{~h}$ in the presence of $10 \% \mathrm{FCS}(\mathrm{A}-\mathrm{C}$ ) or for $3 \mathrm{~h}$ in the absence of FCS (D-F) on the substratum precoated with unmodified collagen $(A, D)$, succinylated collagen $(B, E)$, or methylated collagen $(\mathrm{C}, \mathrm{F})$. Cells were photographed with an Olympus IMT inverted microscope and an Olympus PM-10 AD $35 \mathrm{~mm}$ camera system. $\times 200$ 


\section{Cell Attachment to Non-Heat-Denatured and Heat-Denatured Collagen}

The rate of $\mathrm{L}$ cell attachment to unmodified or chemically modified collagen-coated dishes was nearly the same in the presence or absence of serum (Fig. 3). In contrast, heat denaturation of collagen enhanced the rate of cell attachment in the presence of serum (Fig. 5). The results indicate that the rate of $\mathrm{L}$ cell attachment to a heat-denatured collagen-coated substratum, but not to a non-heat-denatured collagen-coated substratum, is significantly affected by serum.

\section{Effect of Fibronectin on Cell Attachment to Heat-Denatured Collagen}

As stated above, L cell attachment to heatdenatured collagen was mediated by serum. A similar result was obtained for $\mathrm{L}$ cell attachment to heat-denatured collagen which had been treated with purified plasma fibronectin (Fig. 6). This demonstrates the possibility that fibronectin in serum is a mediator for $\mathrm{L}$ cell attachment to heat-denatured collagen.

\section{Effect of Chemical Modifications of Collagen on L Cell Proliferation in Serum-Free Medium}

We investigated the effect of chemical modifications of collagen on cell proliferation. When $L$ cells were cultured in unmodified, succinylated, or methylated collagen-coated dishes in the BSA-supplemented, serum-free medium, they proliferated better in succinylated and methylated collagen-coated dishes than in unmodified collagen-coated dishes (Fig. 7A). Addition of fibronectin to the cultures promoted the proliferation of $\mathrm{L}$ cells both in chemically modified collagen-coated dishes and in unmodified collagen-coated dishes (Fig. 7B). These observations indicate that chemical modifications of collagen side chains significantly affect not only cell attachment but also cell proliferation.

\section{DISCUSSION}

The result of our study indicate that fibroblast attachment and proliferation are markedly affected by structural alterations of collagen used as a substratum.

Chemical modification of the collagen side chains was used to investigate the importance of the net charge of collagen in fibroblast attachment to collagen. Enzyme-solubilized collagen,

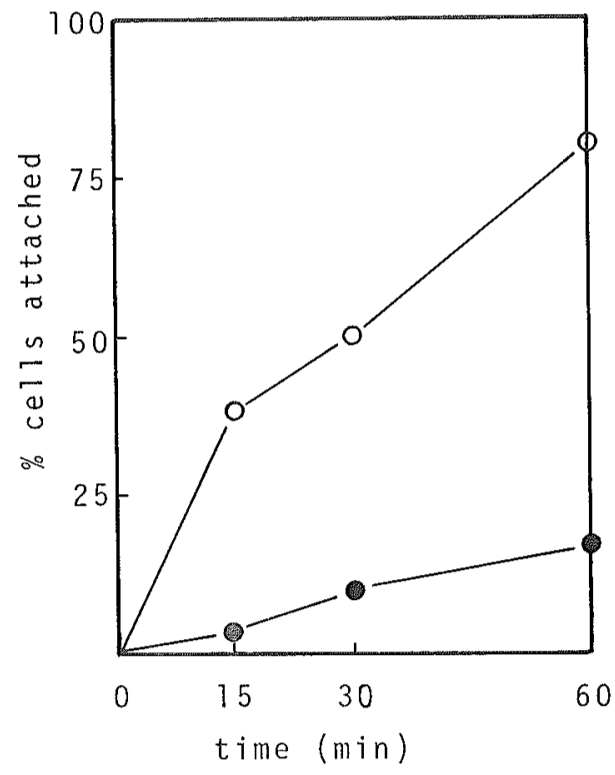

Fig. 5 Time course of $\mathrm{L}$ cell attachment to heatdenatured collagen substratum in the presence $(0)$ or absence $(\bullet)$ of serum

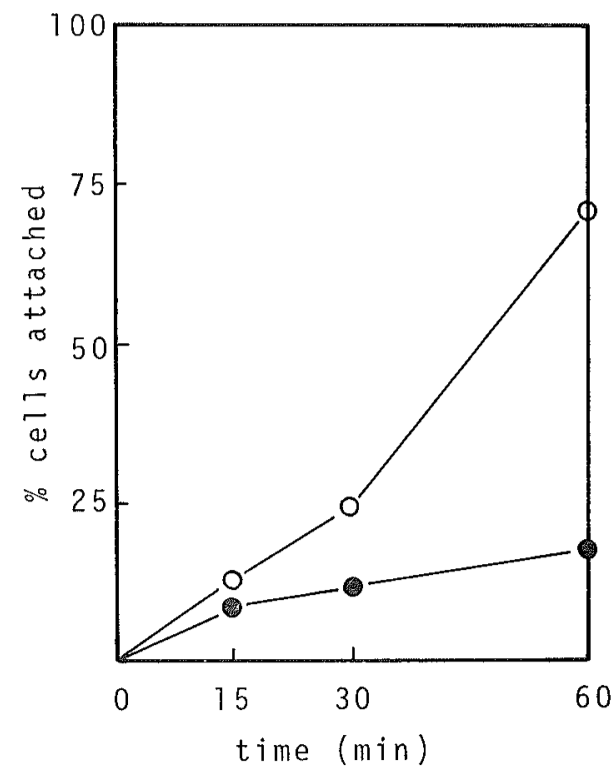

Fig, 6 Effect of fibronectin on $L$ cell attachment to heat-denatured collagen substratum. Heat-denatured collagen-coated dishes were incubated with either HBSS or HBSS containing $100 \mu \mathrm{g}$ of fibronectin per ml. They were then washed twice with HBSS. Cell attachment was determined in the absence of serum as described in Materials and Methods. heat-denatured collagen not pretreated with fibronectin; $O$, heat-denatured collagen pretreated with fibronectin 

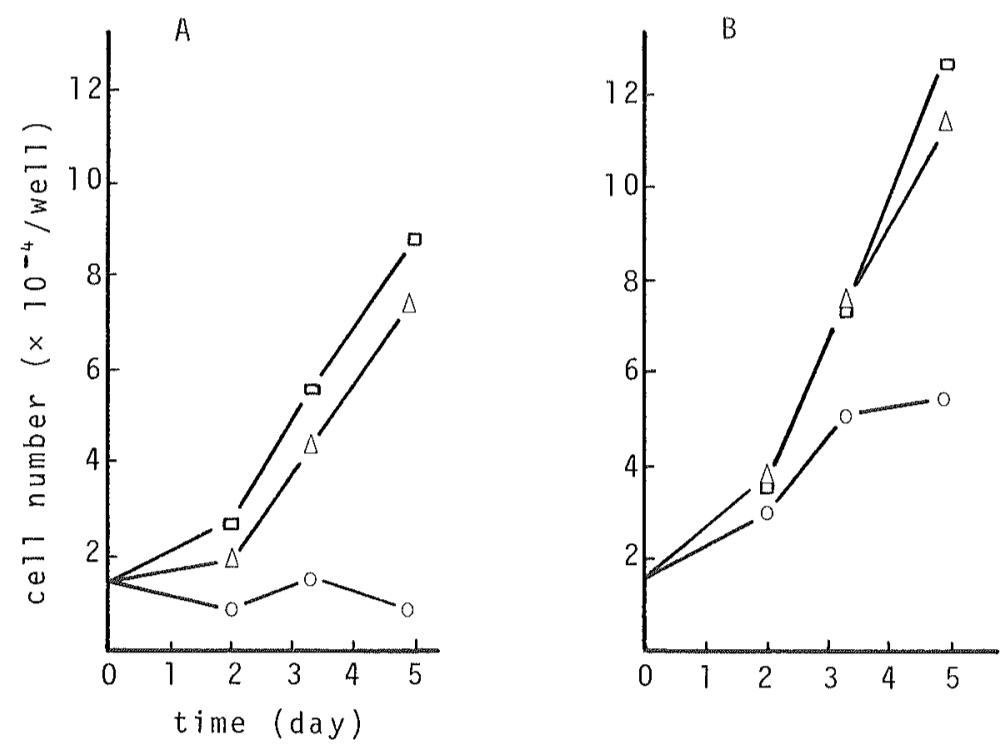

Fig. 7 Effect of chemical modifications of collagen on L cell growth in serumfree medium. L cells $\left(1.5 \times 10^{4}\right.$ cells $)$ suspended in Eagle's MEM supplemented with $1 \% \mathrm{BSA}$ were placed into $16 \mathrm{~mm}$-wells of flat-bottom multiwell plates that had been coated with various collagens and/or fibronectin, and incubated at $37^{\circ} \mathrm{C}$ in a $5 \% \mathrm{CO}_{2}$ atmosphere. A: $O$, unmodified collagen; $\square$, succinylated collagen; $\triangle$, methylated collagen. $B$ : $\bigcirc$, unmodified collagen and fibronectin; $\square$, succinylated collagen and fibronectin; $\Delta$, methylated collagen and fibronectin

with a rigid triple-helical structure, has $\epsilon-\mathrm{NH}_{2}$ and $\mathrm{COOH}$ groups available for chemical modification for special application to biological materials. For example, succinylated and methylated collagens become antithrombogenic and thrombogenic, respectively, as compared to unmodified collagen (13). At pH 7.3 the net charge on unmodified collagen is approximately neutral (Fig. 2). Succinic anhydride can react with collagen, replacing almost $97 \%$ of the amino groups by carboxyl groups (22). Eighty-five percent of the free carboxyl groups of collagen can be esterified with anhydrous methanol containing $\mathrm{HCl}$ (22). Thus, collagen can be converted into a highly charged protein, either negative or positive (Fig. 2), without a change in the basic triple-helical structure of the molecule (Fig. 1). As shown in Fig. 3, chemical modifications of collagen side chains resulted in enhancement of the rate of cell attachment to both succinylated and methylated collagencoated substrata. It has also been observed in our study that succinylation and methylation of collagen induce the enhancement of mouse peritoneal macrophages adhesion (data not shown). Since cells can adhere to and grow on both glass and tissue culture dishes (negatively charged) and polylysine coated surfaces or Cytodex 1 microcarriers (Pharmacia Fine Chemicals Co.) (positively charged), the basic factor governing adhesion and growth of cells is the density of the charges on the culture surface rather than the polarity of the charges $(8,11)$.

Attachment of $L$ cells to the substratum coated with native collagen occurs to nearly the same extent both in the presence and absence of serum (Fig. 3), but attachment to the substratum coated with heat-denatured collagen is significantly enhanced in the presence of serum (Fig. 5). A serum factor, called fibronectin or coldinsoluble globulin, has been shown to promote cell attachment and spreading when applied on a substratum $(6,8,17,24)$. Therefore, we have investigated whether fibronectin is required for the interaction between $\mathrm{L}$ cells and the substrata coated with denatured collagen. As shown in Fig. 6, fibronectin bound to denatured collagen substrata mediates attachment of $L$ cells to the substrata. These findings demonstrate that alteration of the net charge of collagen affects cell attachment directly, whereas conformational change of collagen does this indirectly through fibronectin.

The number of $\mathrm{L}$ cells maintained on un- 
modified collagen or chemically modified collagens in the BSA-supplemented, serum-free medium was 8.8 -fold and 7.4-fold that of cultures maintained on unmodified collagen. Addition of fibronectin to the cultures promoted the proliferation of $\mathrm{L}$ cells both on chemically modified collagens and on unmodified collagen. Our results demonstrate that chemical modifications of collagen side chains not only promote the attachment of $L$ cells to the substrata but also affect cell proliferation. Bottenstein and Sato (1) reported that the addition of plasma fibronectin to serum-free defined medium and precoating the tissue culture dishes with polylysine permitted proliferation of B104 neuroblastoma cells. Insulin, progesterone, and transferrin were, however, required for proliferation in their studies. In contrast, growth factors were not required in our studies with chemically modified collagens. Some interaction between chemically modified collagens and cells may be important for subsequent proliferation. Further studies are presently being carried out to clarify the interaction mechanisms of chemically modified collagen molecules with the cell surface and cytoskeleton.

Received for publication 24 January 1983; and in revised form 16 February 1983

\section{REFERENCES}

1. Bottenstein J.E. and Sato G. H. (1980) Fibronectin and polylysine requirement for proliferation of neuroblastoma cells in defined medium. Exp. Cell Res. 129, 361-366

2. Elsdale T, and Bard J. (1972) Cellular interactions in mass cultures of human diploid fibroblasts. Nature 236, 152-155

3. Engvall E. and Ruoslahti E. (1977) Binding of soluble form of fibroblast surface protein, fibronectin, to collagen. Int. J. Cancer 20, 1-5

4. Engvall E., Ruoslahti E. and Miller E. J. (1978) Affinity of fibronectin to collagens of different genetic types and to fibrinogen. $J$. Exp. Med. 147, 1584-1595

5. Gospodarowicz D. and Ill C. R. (1980) Do plasma and serum have different abilities to promote cell growth? Proc. Natl. Acad. Sci. USA 77, 2726-2730

6. Grinnell F. and Minter D. (1978) Attachment and spreading of baby hamster kidney cells to collagen substrata: Effects of cold-insoluble globulin. Proc. Natl. Acad. Sci. USA 75, 4408 4412

7. HauschKa S. D. and Konigsberg I. R. (1966) The influence of collagen on the development of muscle clones. Proc. Natl. Acad. Sci. USA 55, 119-126
8. Hirtenstein M., Clark J. and Lindgren G. (1980) Microcarriers for animal cell culture: a brief review of theory and practice. Develop. Biol. Standard 46, 109-116

9. KaKade M. L. and Liener I. E. (1969) Determination of available lysine in proteins. Anal. Biochem. 27, 273-280

10. KLEBE R. J. (1974) Isolation of a collagendependent cell attachment factor. Nature $\mathbf{2 5 0}$, 248-251

11. Maroudas N. G. (1975) Adhesion and spreading of cells on charged surfaces. J. Theor. Biol. 49 , $417-424$

12. Michalopoulos G. and Pitot H. C. (1975) Primary culture of parenchymal liver cells on collagen membranes. Morphological and biochemical observations. Exp. Cell Res. 94, $70-78$

13. Miyata T., Schwartz A., Wang C. L., Rubin A. L. and Stenzel K. H. (1976) Deposition of platelets and fibrin on chemically modified collagen hollow fibers. Trans. Amer. Soc. Artif. Int. Organs 22, 261-267

14. Murray J. C., Stingl G., Kleinman H. K., Martin G. R. and Katz S. I. (1979) Epidermal cells adhere preferentially to type IV (basement membrane) collagen. J. Cell Biol. 80, 197-202

15. Nakagawa M. and URIST M. R. (1977) Chondrogenesis in tissue cultures of muscle under the influence of a diffusible component of bone matrix. Proc. Soc. Exp. Biol. Med. 154, 568-572

16. Nishihara T. and MiYata T. (1962) The effects of proteases on soluble and insoluble collagens and the structure of the insoluble collagen fiber. Collagen Symposium 3, 66-93

17. Pearlstein E. (1976) Plasma membrane glycoprotein which mediates adhesion of fibroblasts to collagen. Nature 262, 497-500

18. Postlethwaite A. E., Seyer J. M. and Kang A. H. (1978) Chemotactic attraction of human fibroblasts to type I, II, and III collagens and collagen-derived peptides. Proc. Natl. Acad. Sci. USA 75, 871-875

19. Salomon D. S., Liotta L. A. and Kidwell W. R. (1981) Differential response to growth factor by rat mammary epithelium plated on different collagen substrata in serum-free medium. Proc. Natl. Acad. Sci. USA 78, 382-386

20. Schor S. L. and CourT J. (1979) Different mechanisms in the attachment of cells to native and denatured collagen. J. Cell Sci. 38, 267-281

21. TANFORD C. (1962) The interpretation of hydrogen ion titration curves of proteins. $A d v$. Prot. Chem. 17, 69-165

22. Wang C.-L., Miyata T., Weksler B., Rubin A. L. and Stenzel K. H. (1978) Collagen-induced platelet aggregation and release. I. Effects of side-chain modifications and role of arginyl residues. Biochim. Biophys. Acta 544, 555-567

23. WeIss P. (1975) Experiments on cell and axon orientation in vitro: the role of colloidal exudates 
in tissue organization. J. Exp. Zool. 100, 353386

24. Yamada K. M. and Olden K. (1978) Fibronec- tins-adhesive glycoproteins of cell surface and blood. Nature 275, 179-184 